have had perplexing results, and beneficial results have not been confirmed. Chlorambucil has had beneficial effects on liver function test values and liver histology but no effect on survival. ${ }^{18}$ Colchicine has improved liver function and reduced mortality at four years but surprisingly had no effect on liver histology. ${ }^{19}$ Cyclosporin has reduced plasma alkaline phosphatase and aminotransferase activities in a small group of patients but caused renal damage in each case. ${ }^{20}$ Ursodeoxycholic acid has improved liver function test values but not histology over two years in an uncontrolled trial. ${ }^{21}$

There is little in all this to excite doctors or to raise the hopes of patients. Patients without symptoms have a good prognosis and prolonged treatment with drugs does not seem warranted, while those with advanced disease and liver failure would seem unlikely to benefit from drug therapy. Doctors who feel that they must offer some treatment directed at the disease should limit their efforts to patients with symptoms who do not have liver failure; they could use azathioprine with some hope of benefit and with reasonable chances of avoiding serious side effects. Sceptics would be justified in doing nothing but might consider contributing to controlled trials.

Consultant Physician,

N D C FINLAYSON

Gastrointestinal and Liver Service,

Royal Infirmary,

Edinburgh EH3 9YW
1 Kaplan MM. Primary biliary cirrhosis. N Engl f Med 1987;316:521-8.

2 Christensen E, Crowe J, Doniach D, et al. Clinical pattern and course of disease in primary biliary cirrhosis based on an analysis of 236 patients. Gastroenterolozy 1980;78:236-46.

3 Schaffner F, Klion FM, Latuff AJ. The long term use of cholestyramine in the treatment of primary biliary cirrhosis. Gastroenterology 1965;48:293-8.

4 Datta DV, Sherlock S. Cholestyramine for long term relief of the pruritus complicating intrahepatic cholestasis. Gastroenterology 1966;50:323-32.

5 Javitt NB. Timing of cholestyramine doses in cholestatic liver disease. N Engl $\mathcal{f}$ Med 1974;290:1328-9.

6 Hanid MA, Levi AJ. Phototherapy for pruritus in primary biliary cirrhosis. Lancet 1980;ii:530. Cohen LB, Ambinder EP, Wolke AM, Field SP, Schaffner F. Role of plasmapheresis in primary biliary cirrhosis. Gut 1985;26:291-4.

Duncan JS, Kennedy HJ, Triger DR. Treatment of pruritus due to chronic obstructive live disease. BrMed f 1984;289:22.

9 Beckett GJ, Dewhurst N, Finlayson NDC, Percy-Robb IW. Weight loss in primary biliary cirrhosis. Gut 1980;21:734-8.

10 Arnaud SB. 25-Hydroxyvitamin $D_{3}$ treatment of bone disease in primary biliary cirrhosis. Gastroenterology 1982;137:137-40.

11 Shepherd AN, Bedford GJ, Hill A, Bouchier IAD. Primary biliary cirrhosis, dark adaptometry, electro-oculography and vitamin A state. BrMed $\mathcal{F}$ 1984;289:1484-5.

12 Busuttil RW. Liver transplantation today. Ann Intem Med 1986;104:377-89.

13 Starzl TE, Todo S, Gordon R, et al. Liver transplantation in older patients. $N$ Engl $\mathcal{J}$ Med 1987;316:484-5.

14 Roll J, Boyer JL, Barry D, Klatskin G. The prognostic importance of clinical and histologica features in asymptomatic and symptomatic primary biliary cirrhosis. N Engl f Med 1983;308: $1-7$.

15 Howat HT, Ralston AJ, Varley $\mathrm{H}$, Wilson JAC. The late results of long-term treatment of primary biliary cirrhosis by corticosteroids. Reoue International d'Hepatologie 1966;16:227.

16 Christensen $E$, Neuberger J, Crowe J, et al. Beneficial effect of azathioprine and prediction of prognosis in primary biliary cirrhosis: final results of an international trial. Gastroenterology 1985;89:1084-91.

17 James OFW. D-penicillamine for primary biliary cirrhosis Gut 1985;26:109-13.

18 Hoofnagle JH, Davis GL, Schafer DF, et al. Randomized trial of chlorambucil for primary biliary cirrhosis. Gastroeviterology 1986;91:1327-34.

19 Kaplan MM, Alling DW, Zimmerman HJ, et al. A prospective trial of colchicine for primary biliary cirrhosis. N Engl f Med 1986;315:1448-54.

20 Routhier G, Epstein O, Janossy G, Thomas HC, Sherlock S. Effects of cyclosporin A on suppressor and inducer T lymphocytes in primary biliary cirrhosis. Lancet 1980;ii:1223-6.

21 Poupon R, Chrétien Y, Poupon RE, Ballet F, Calmus Y, Darnis F. Is ursodeoxycholic acid an effective treatment for primary biliary cirrhosis? Lancet 1987;i:834-6.

\title{
JPAC: a test for manpower planning
}

Successful medical manpower planning has been handicapped by the many years it takes to train doctors for career posts. During this long gestation unpredictable developments may make nonsense of seemingly rational decisions. One important unpredictable factor has been the variable number of doctors in academic and research medicine. Uncertainty about the effect of these doctors on manpower planning prompted the Department of Health and Social Security, the Committee of Vice Chancellors and Principals, the Medical Research Council, and the Joint Consultants Committee to set up the Joint Planning Advisory Committee (JPAC). JPAC's 1986 report has now been published, providing an opportunity to assess progress on its three initial tasks in improving the career structure for hospital doctors.

Firstly, the committee set out to determine the correct number of senior registrar posts needed, both NHS and honorary, by specialty or "specialty group." This seems easy as the relation between senior registrar and consultant posts is direct and the transition period short. JPAC is collecting data on what district health authorities think about their consultant expansion programmes, which is a practical start. But to use the information as the sole basis for calculating the "right" number of senior registrars is a poor substitute for proper planning. Such an approach-which will be even more unsatisfactory if applied to registrars-implies an inability to lead the system. Furthermore, defining specialties and specialty groups is difficult because medical care has become so complex. This is particularly so in medicine and the medical specialties, where the Joint Committee on Higher Medical Training recognises no fewer than 75 different kinds of senior registrar posts. For example, the number of senior registrar posts in renal medicine is an inadequate guide to career opportunities and health care needs in nephrology, general medicine with an interest in nephrology, academic nephrology, or research in kidney disease. More detailed analysis is daunting but hard to avoid, if only because most future consultants in general medicine will be a byproduct of the training of senior registrars in many medical specialties. Fortunately, since its 1986 annual report JPAC has proposed tentative guidelines for resolving this complex matter.

Secondly, JPAC has examined the distributions of NHS and honorary senior registrar posts. Undisclosed or uncounted research and academic posts with senior registrar status have bedevilled attempts to plan, and the priority was to define the size of the problem. Since JPAC began work, however, its secretariat has reached two interesting conclusions: firstly, that it may be almost impossible to count accurately or to control the number of research posts at or about senior registrar level; and, secondly, that it may be unnecessary to do so as the distortion of manpower and career planning is more imaginary than real. Despite its first disclaimer JPAC has produced useful figures for the numbers and distribution of such posts, so far better information than before is now publicly available. There is no limit to the number of academic and research posts that can be created without distorting the career structure-so long as they are not recognised for training. Problems arise when all or part of the time spent in such a post counts towards accreditationas is the case with some registrar training-as an alternative to experience in an NHS senior registrar post. Indeed, JPAC has conceded that it intends "to find out more about 
the number of such posts and the part they play in career progression." The factors determining competition for consultant posts are the number of people who at any one time occupy posts with training recognition, and the minimum period required in such posts. Without control over the first of these and clear understanding of the second the system is unmanageable.

The third of JPAC's tasks concerned quotas of posts for regions. For this the committee devised an allocation formula giving a weighting of $30 \%$ to the number of medical and dental students in the region, $50 \%$ to the regional population adjusted according to the formula of the Resource Allocation Working Party, and only $20 \%$ to the expected number of consultant vacancies in the region. This formula, intended to offer rough justice, weights student numbers more than was originally proposed. Though there may be a discernible link between numbers of undergraduates and numbers of senior registrars (and perhaps in some places senior registrars are relied on more than they should be to teach students), the relation seems too tenuous to justify a substantially increased weighting. Again the JPAC report, commenting on the high concentration of senior registrar posts in London, refers to the raison d'être of the London postgraduate teaching hospital special health authorities as being "precisely to provide a national training resource." Historical reasons of this kind are not a sound basis for future policies. Good training centres, research facilities, and career opportunities are far more evenly spread throughout the regions than are senior registrars. If there is not a self evident and acknowledged need for change in this state of affairs JPAC has little purpose. The formula requires no region to lose more than one senior registrar a year in a specialty and provides for posts funded by the MRC and similar bodies to be excluded from the regional quota allocations. On this basis the rate of change must be disappointingly slow for many regions, and the first year's allocations show little change except in specialties in which the total number of senior registrars across the country has increased. In any case the committee's concentration on senior registrars is relatively unimportant in the wider context of the profession's problems with its career structure.

All that said, JPAC has made a useful start in analysing the problems and assembling necessary data at a time when the DHSS, the universities, the research establishment, and the profession are all under pressure. Unfortunately, previous failures to act decisively on manpower because of misunderstanding, intransigence, vested interests, or sheer inability to manage the system give scant cause for optimism. The outcome for JPAC's work may well be a test of whether medical manpower planning is to be treated seriously in the NHS.

J PARKHOUSE

Director

Medical Careers Research Group,

Churchill Hospital,

Oxford OX3 7LJ
If correctly managed a young woman with a malignant ovarian germ cell tumour has a better than $85 \%$ chance of being cured and a good chance of remaining fertile. These malignant tumours account for about $3 \%$ of all ovarian neoplasms, and half are dysgerminomas. Doctors need to revise their belief that some histological types have a hopeless prognosis. In fact a treatment can be selected to preserve fertility as well as life.

Gynaecologists should consider that an ovarian mass may be a germ cell tumour when the patient is under 30 , when the mass has solid areas on ultrasound examination, and when certain tumour markers are produced. Serum assays detect raised activity of placental alkaline phosphatase in many patients with dysgerminomas and raised concentrations of $\alpha$ fetoprotein or human chorionic gonadotrophin, or both, in most patients with malignant non-dysgerminomatous germ cell tumours.

For patients with ovarian germ cell tumours a unilateral salpingo-oophorectomy is preferable to a more radical operation. The entire peritoneal contents, however, require inspection through a midline incision, washings are needed for cytological examination, and if it looks suspicious the contralateral ovary requires biopsy. If a pure dysgerminoma is found and there is no clinical evidence of spread, a normal computed tomogram, and normal concentrations of tumour markers then the patient may simply be closely followed up rather than actively treated..$^{23}$ Patients without metastases will avoid toxic treatment, and relapse can be successfully treated.
Many patients with non-dysgerminomatous tumours that have not metastasised have hitherto been treated with vincristine, actinomycin $\mathrm{D}$, and cyclophosphamide, and about $80 \%$ have survived long term. ${ }^{4}$ More toxic treatment with cisplatin, vinblastine, and bleomycin leads to almost $100 \%$ survival. ${ }^{5}$ Because many would probably have survived without chemotherapy and relapses can now be treated, close surveillance is being studied as a treatment option. ${ }^{6}$

When a dysgerminoma has metastasised only to the pelvic area radiotherapy will free about $90 \%$ of patients from disease, but it is less effective against more advanced disease..$^{23} \mathrm{~A}$ similar result can be obtained in patients with advanced dysgerminomas given combination chemotherapy including cisplatin and etoposide, ${ }^{6-8}$ and-in contrast to those receiving radiotherapy-most remain fertile. ${ }^{9}$

The results are as good in patients with advanced nondysgerminomatous tumours provided the patients have not already received radiotherapy or chemotherapy..$^{5-7}$ Cisplatin, vinblastine, and bleomycin are more effective than vincristine, actinomycin D, and cyclophosphamide, and replacing vinblastine by etoposide reduces the toxicity..$^{410}$ It is not clear whether these regimens are as effective as cisplatin, vincristine, methotrexate, and bleomycin alternating with actinomycin D, cyclophosphamide, and etoposide especially in patients with widespread metastases or high concentrations of tumour markers, or both. ${ }^{6}$. Residual masses must be resected and examined to confirm that they do not contain active tumour or differentiated teratoma.

Because of the rarity and curability of malignant ovarian 